\title{
Flood Prediction and Management for Damage Reduction and Environmental Protection in North Khorasan
}

\author{
Ali Elahi Goland \& GholamAli Kamali \\ Phd student in meteorology, Islamic Azad University, Science and Research Branch, Tehran, \\ Iran and expert of meteorological organization \\ Associate professor of Meteorological Department, Islamic Azad University, \\ Science and Research ranch, Tehran, Iran.
}

\begin{abstract}
Flood is the most common natural hazards in northern KHorasan. So, the most hazardous floods from 2006 to 2013 in this region are selected. In North KHorasan environment and agricultural crops take the most damage of flood. Results shows that if cold and humid air mass from upper latitude with high pressure on Caspian sea combined by warm and humid air mass of Indian ocean and Oman sea, this can make heavy rainfall and flash flood. Each one of these air masses with appropriate dynamic conditions can create a heavy rainfall. However, instability indices were calculated by Mashhad's Skew-T diagram. SODAR outputs are used to investigate the unstable atmospheric conditions. All indices show a high probability of instability and thunderstorm in these days. This study appears that although there is not upper atmospheric station in northern KHorasan, but we can use Mashhad Skew-T diagrams for strong atmospheric system in North East of Iran. This finding will help forecaster for better prediction.Finally, we found that Timely flood forecasting and management can help todamage reduction and protect the environment.
\end{abstract}

Keywords: Flood, Heavy rainfall, Instability indices, Skew-T, Thunderstorm,Environmental protection

\section{INTRODUCTION}

Flash floods induced by extreme rainfall events represent one of the most life-threatening phenomena in the North KHorasan. One of the main challenges encountered during the warm months of the year, is the occurrence of flash floods due to heavy rain showers (Fritsch and Carbone, 2004). The $\mathrm{K}$ (George, 1960) index has been regarded as one of the significant predictors of heavy rain showers under these circumstance. Here, all rain showers occurred could be categorized as one of the four general synoptic situations, proposed by Haraguchi (1977). Analysis of Synoptic patterns and Skew-T map shows slow pluvial systems could lead to flood in Yazd (Omidvar, 2009). In the study conducted by Rebora (2013), the role of the key factors contributing to the rain shower events over complex orographic ground masses (e.g., unstable air masses, moist low-level jets, steep Orography, and a slow-evolving synoptic pattern) have been evaluated. There prerequisites of large-scale precipitation events are fairly overviewed. Yet, little is known on the mechanisms governing the exact location of precipitation events and the factors that lead to phenomenal rainfall records (Ricard et al. 2012). Most rainfall events occurring in the warm months of the year in the unitedstates stem from the meso - scale convective systems (Schumacher and Johnson 2005, 2006). Tajbakhsh (2010) demonstrate that thunderstorm can be predicted by MM5 outputs, Synoptic patterns and Skew-T map. Elahi Gol and Bidokhti (2014) investigate on gust front in Bojnord airport of North Khorasan provience. This issue appears that turbulence in Bojnord airport can be so dangerous for aero meteorology and airplane.

\section{Methodology}

In these study synoptic maps, Skew-T diagram, SODAR output and synoptic observation from meteorological organization of Iran and flood information from natural resource administration of North KHorasan are used to investigate the heavy rainfall. Instability indices also calculated for better prediction and reduce hazard. We used 14 dangerous floods in North KHorasan from 2006 to 2013 according table1.

In this section for two selected flood, different level of synoptic maps are derived from NCEP-NCAR database and forecasting center of meteorological organization of Iran and then analyzed by Skew-T diagrams and SODAR outputs. The position of North KHorasan is in figure 1. 


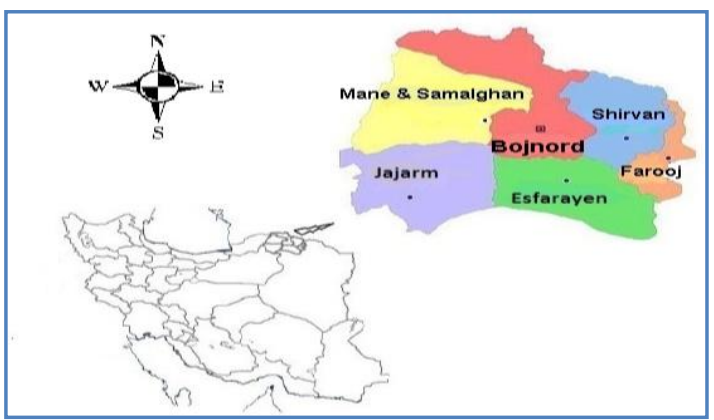

Fig1. Position of North KHorasan province in Iran

\subsection{The 3 may 2011 event}

In this day, surface map shows the thermal low pressure on Pakistan which has been stretched to center of Iran. This cause that warm and moist air masses of Indian Ocean and Oman sea expands on the Alborz mountains and make convective precipitation. On the other hand, high pressure on Caspian Sea transfers the moisture on Northeast of Iran. So we have two humid sources in North KHorasan that enhance conditions for heavy rainfall and floods. Favorable pressure gradient in the region helps to exacerbate the situation. The maps of 500-HpaGeopotential height demonstrate the deep trough by high gradient and almost vertical direction contours that provide a good condition in upper level for heavy rainfall and floods. Check other maps like 850, 700, 300 and 200-Hpa on this day, show strong dynamic conditions at different levels of the atmosphere for dangerous events. We can calculate instability indexes from Skew-T diagrams. These kinds of charts created from radiosonde data of Mashhad. In this day Ki index is 34.1 that show noticeable instability. Second index is TTI (Total Total Index) that is equal 52 and it is mean the suitable condition for thunderstorm. In this event lifted index (LI) is -0.91 that if LI between zero and -2 , there is a chance of rain showers. Another indicator is bad weather that named Sweat index, which here is equal to 168.21 and tell about potential of showers and thunderstorms. In overall, these measures can be evaluated to predict occurrence of thundershower. Figure 2 determines wind velocity vector output of SODAR that imply the existence of unstable conditions at height of 40 to 600 meters. In this figure, the vertical movement and obvious changes in wind speed can be seen in the time of thunderstorm.

Table1. Dangerous floods in North KHorasan between 2006- 2013.

\begin{tabular}{|l|l|l|l|l|}
\hline Date of flood & City & Basin name & River name & discharge $(\mathrm{m} 3 / \mathrm{s})$ \\
\hline $2006 / 8 / 31$ & Jajarm & Gorganrood & Dasht & 100 \\
\hline $2007 / 4 / 15$ & Esfarayen & Atrak & Atrak & 120 \\
\hline $2007 / 6 / 2$ & Shirvan & Atrak & Gelyan & 100 \\
\hline $2007 / 6 / 5$ & Shirvan & Atrak & Atrak & 50 \\
\hline $2008 / 9 / 17$ & Bojnord & Atrak & Atrak & 450 \\
\hline $2009 / 5 / 18$ & Esfarayen & KavireMarkazi & Kaleshur & 105 \\
\hline $2009 / 5 / 31$ & Shirvan & Atrak & Atrak & 45 \\
\hline $2009 / 6 / 9$ & Bojnord & Atrak & Atrak & 47.5 \\
\hline $2010 / 5 / 14$ & Shirvan & Atrak & Atrak & 450 \\
\hline $2010 / 6 / 19$ & Garme & KavireMarkazi & Asadli & 80 \\
\hline $2011 / 5 / 3$ & Bojnord & Atrak & Gelyan & 65 \\
\hline $2011 / 5 / 8$ & Shirvan & Atrak & Namanlu & 60 \\
\hline $2011 / 8 / 24$ & Shirvan & Atrak & Gezbashi & 130 \\
\hline $2013 / 9 / 25$ & Mane and Samalghan & Atrak & \\
\hline
\end{tabular}

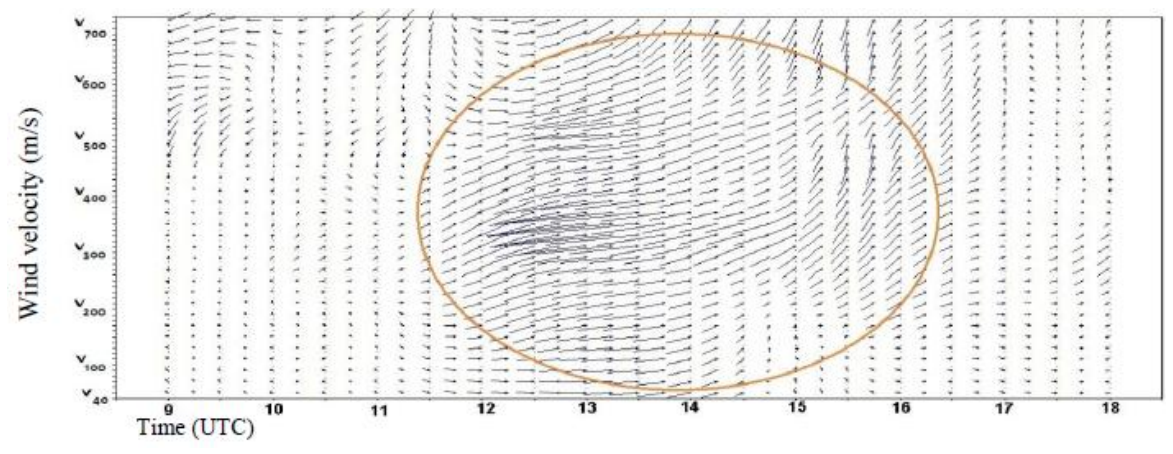

Fig 2. Wind velocity vector of Bojnord from 40 to $700 \mathrm{~m}$ height in 3 may 2011 


\subsection{The 25 September 2013 event}

On the 25 September 2013shower Rain, hail and floods occurred in the central section of Mane and Samalghan in west of North KHorasan. Horticultural and agricultural land, buildings, roads and utilities to some villages was damaged. Three people lost their lives and 187 head of cattle of the villagers died in this day. Figure 3 (A) shows the high pressure that transferee the moisture from Caspian Sea and cold air from the high latitudes to the North KHorasan. Meanwhile, low pressure has been located in the central and eastern half of the Iran that drawn to neighboring countries likes Pakistan. This could transfer the warm and humid air masses from the Persian Gulf and Oman Sea to the North-East of Iran. Combination of these two air masses can make heavy rainfall and floods in northern KHorasan. We can see Low pressure in Northwest of Russia in Figure 3 (B). Deep trough with good gradient of pressure in this maps make rain shower. Other maps in upper level show the suitable dynamic condition for thunderstorm and rain shower.

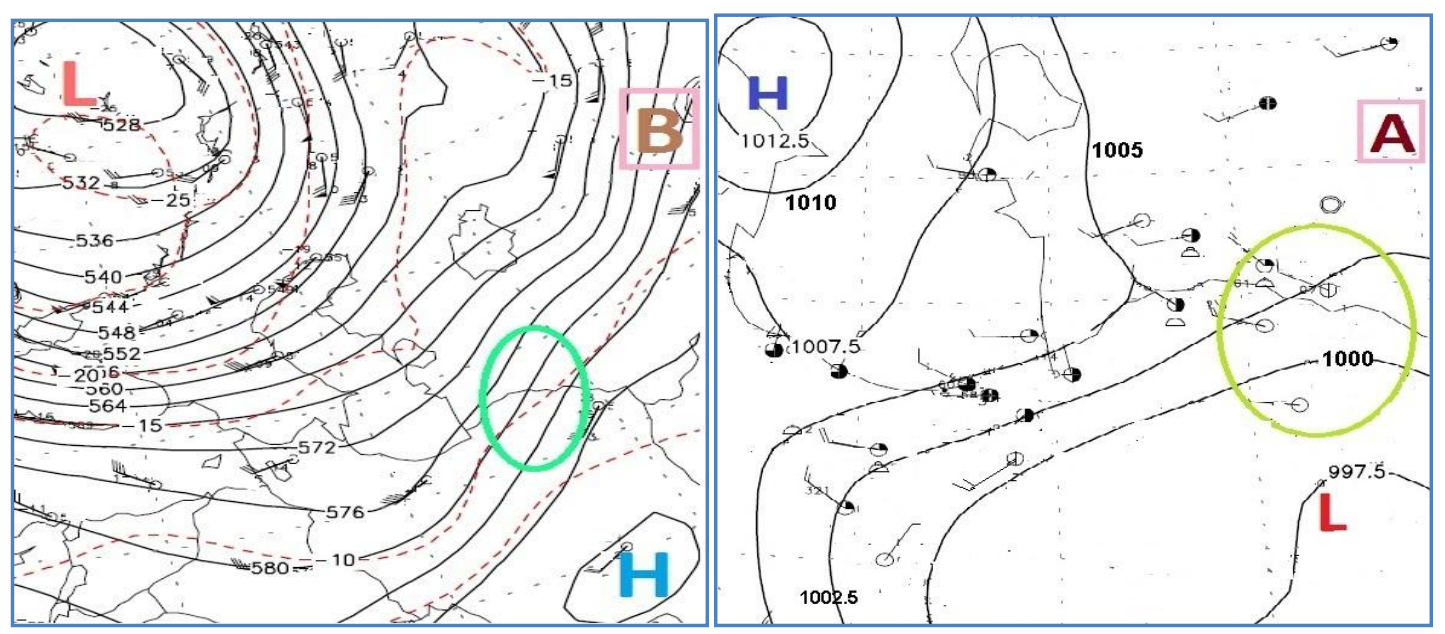

Fig 3. (A) Surface map; B) 500-HPa map at 12UTC in 25 September 2013 (dashed line is temperature)

All indicators in skew-T diagrams of 25 September 2013 show unstable atmospheric condition. While $\mathrm{Ki}$ index is greater than 20, atmosphere will be unstable. The value of $\mathrm{Ki}$ is 20.3 for this event. TTI index is equal to 52.2 , indicating the possibility of severe storms. $\mathrm{Li}$ index is -0.74 that means unstable atmosphere. Sweat index is 186.83 and indicates the condition of showers and thunderstorms in this day. SODAR output in figure 4 is average of wind velocity vector for height 40 to 700 meter on the 25 September 2013. We can see the turbulence, upward and downward motion along afternoon and especially in time of flood.

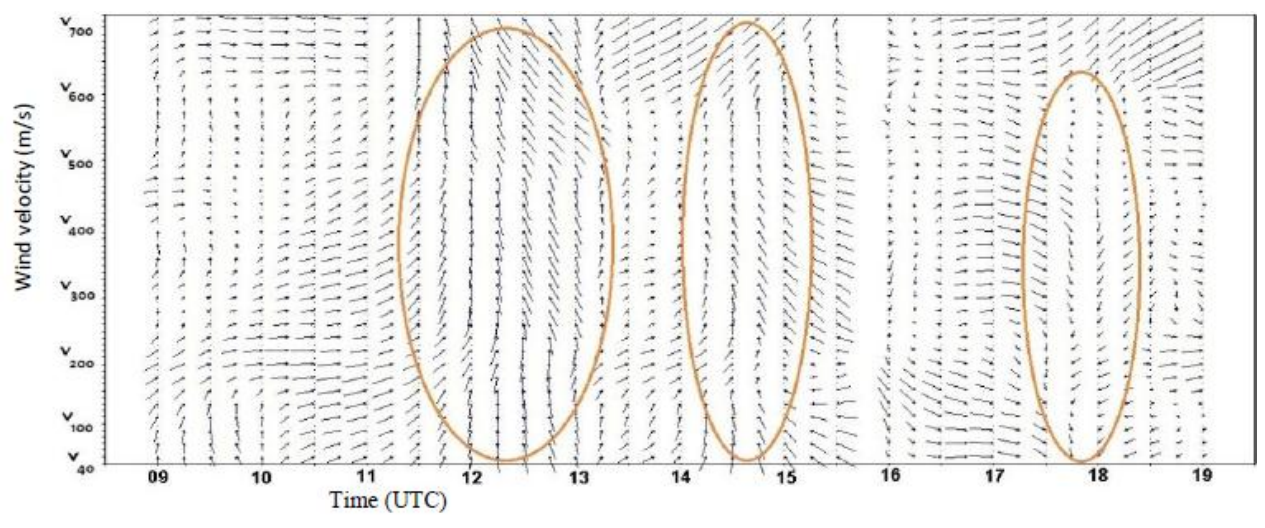

Fig 4. Average of wind velocity vector for height of 40 to 700 meter in 25 September 2013

Our investigation shows that most of floods in North KHorasan occurred in spring and summer. So, these hot and humid seasons are suitable for shower rainfall and thunderstorm. Comparison of mean monthly precipitation and maximum daily precipitation in 1977 to 2013 according figure 5demonstrate that there are a high difference in hot season from June to September. This shows that if humid air mass comes to this region, the warm surface of ground (especially in afternoon) can make a good vertical motion and appropriate state for heavy rainfall. Finally, with attention to North KHorasan topography's, above conditions lead to flood. 


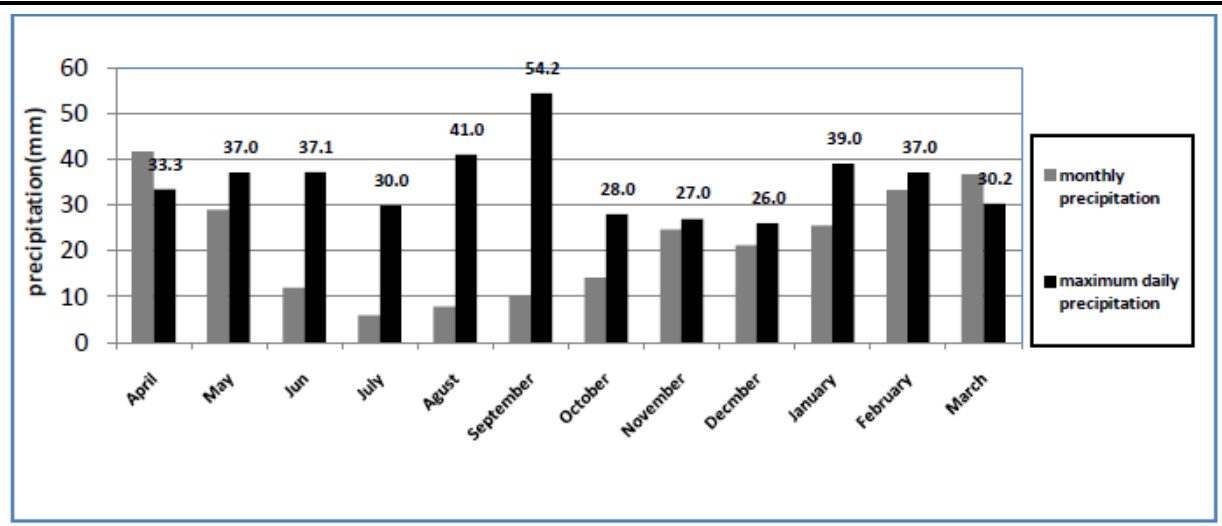

Fig 5. Comparison of mean monthly precipitation and maximum daily precipitation (1977-2013)

\section{Conclusion}

The hot season in North KHorasan is from June to September. Most people, especially farmer's dose not expected rainfall in this region with seasonal river, while the maximum difference between the average monthly precipitation and maximum daily precipitation occurs in this period, therefore the most losses will be occurred. So, agricultural crops take the most damage of flood. The most hazardous floods in this region are selected between 2006 till 2013.Results shows that if cold and humid air mass from upper latitude with high pressure on Caspian sea combined by warm and humid air mass of Indian ocean and Oman sea, this can make heavy rainfall and flash flood. Each one of these air masses with appropriate dynamic conditions can create a heavy rainfall. However, instability indices were calculated by Mashhad's Skew-T diagram. SODAR outputs are used to investigate the unstable atmospheric conditions and vertical movement. All indices show a high probability of instability and thunderstorm in these days. This study appears that although there is not upper atmospheric station in northern KHorasan, but we can use Mashhad Skew-T diagrams for strong atmospheric system in North East of Iran. This finding helps to forecaster for better prediction and fewer hazards in future. Therefore, timely forecasting and flood management will help to protect the environment.

\section{REFERENCES}

[1] Elahi Gol, A., Bodokhti, A.A. 2014. Iranian air transportation, pathology and challenges conference, 20- 21 may 2014. Oral presentation.

[2] Fritsch J. M., and Carbone R. E.2004. Improving quantitative precipitation forecasts in the warm season: A USWRP research and development strategy. Bull. Amer. Meteor. Soc.; 85: 955-965.

[3] George, J. J.1960. Weather Forecasting for Aeronautics. Academic Press; 673 pp.

[4] Haraguchi, P.1977. Forecasting floods in Hawaii (excluding Hawaii Island). NOAA Tech. Memo. NWSTM PR-16; 30 pp.

[5] Omidvar k.2009. Evaluation on floods basis on synoptic positions in Yazd. Geographical research, Mashhad; 88: 137-165.

[6] Rebora N, Molini L, Casella E, Comellas A, Fiori E, Pignon F, Siccardi F, Silvestro F, tanelli S and Parodi A.2013. Extreme Rainfall in the Mediterranean: What Can We Learn from Observations ?. Hydrometeorology; 14: 906-922.

[7] Ricard, D., V. Ducrocq, and V. Auger. A. 2012. climatology of the Mesoscale environment associated with heavily precipitating events over a north-western Mediterranean area. J. Appl. Meteor. Climatology ; 51: 468-488.

[8] Schumacher, R. S., and R. H. Johnson.2005. Organization and environmental properties of extreme-rain-producing Mesoscale convective systems. Mon. Weather. Rev.; 133: 961-976.

[9] Schumacher, R. S., and R. H. Johnson.2006. Characteristics of United States extreme rain events during 1999-2003. Weather. Forecasting; 21: 69-85.

[10] Tajbakhsh S, Ghafariyan P and Mirzaei E.a.2010. Method for predicting the occurrence of thunderstorms with two case study projects. Geophysics Journals; 35 (4): 147-166. 